\title{
A Good Night's Sleep: A Narrative Review from Islamic Perspectives in Relation to Modern Sciences
}

\author{
Zaswiza Mohamad Nor ${ }^{1,2}$,Nurul Nabilah Yusoff ${ }^{1}$, Fasiha Ruhila Fakhrol Razi $^{1}$,Nurul Atiqah Sanusi ${ }^{1}$ \\ ${ }^{1}$ Kulliyyah of Pharmacy, International Islamic University Malaysia Kuantan \\ ${ }^{2}$ Faculty of Pharmacy and Health Sciences, Universiti Kuala Lumpur Royal College of Medicine Perak, No 3, \\ Jalan Greentown, 31200 Ipoh, Perak, Malaysia.
}

\begin{abstract}
As a biological universal, it is easy to overlook the degree to which culture and religion shape how people sleep, and how quality sleep is conceptualized. In the Western world, sleep hygiene tips are important for an individual to get "a good night's sleep". Meanwhile, sleep is also important from an Islamic perspective, which, the Quran and Hadith discuss on its types, importance and quality practices. In modern sciences, sleep deprivation is regarded as a significant health issue, however from an Islamic point of view, long sleep hours alone do not determine the efficiency of sleep, but rather it depends on various other factors and follows the sleeping etiquettes of Prophet Muhammad (PBUH). This narrative review was conducted to highlight sleep from Islamic perspectives in relation to modern sciences. Selected articles discussing sleep from Islamic perspectives and modern sciences were reviewed and summarized. These articles were retrieved from searches of computerized databases and search engines using keywords "Sleep from Islamic perspective", "Sleep in modern science", "Sleep hygiene", "Western world and sleep", "Sleep deprivation" and "Quality sleep". A number of six studies were selected $(n=6)$. Analyses found that a productive Muslim sleep routine is divided into three parts; one-third, respectively, for Allah, ourselves and sleep. Sleep hygiene was emphasized and discussed from the Islamic perspectives and the relation with modern sciences: performing ablution and supplicate before sleep, could prepare the body for a deep sleep; dusting the bed before sleep, would get rid of insects that lead to scabies; turning-off lights before sleep to maintain dark environment, could prevent disruption to normal circadian rhythms; early bedtime and early wake-up time, would ensure adequate sleep thus lower the risk of getting chronic diseases; washing the hands after waking -up would get rid of germs accumulated during sleep; and, lying down on the right side is to prevent snoring and to avoid the heart under pressure of the right lung (if lying on the left side). People should not abandon sleep as an important requirement. What has been described in the Quran and Hadith are corresponded with sleep hygiene as identified by modern sleep scientists. Prophet Muhammad (PBUH) also stressed the importance of sleep for good health, and in the Quran, sleep is described as a blessing from Allah and stressed the importance of the alteration of night and day.
\end{abstract}

KEYWORDS: Quality sleep, Sleep hygiene, Sleeping etiquettes, Islamic view, Modern Sciences

\section{INTRODUCTION}

Al-Isfahani ${ }^{1}$ defined sleep as follows: "to soften the nerves of the brain, with the moisture of oxygen to the brain". Meanwhile, according to al-Kindi: "Sleep is to allow the soul to be used by all senses. If we do not see, hear, feel, taste, touch, without any usual illness (causing it) and we are in a normal state, then we are said to be sleeping". ${ }^{2}$. In modern science, sleep is defined as the body being in an unconscious state, where eyes are closed because of resting ${ }^{3}$, and scientists have the perception that sleep is a subconscious state where an individual can

Corresponding author:

Zaswiza Mohamad Noor,

Faculty of Pharmacy and Health Sciences,

Universiti Kuala Lumpur Royal College of Medicine

Perak, No 3, Jalan Greentown,

31200 Ipoh, Perak, Malaysia.

Telephone: +6052432635

Email: zaswiza@unikl.edu.my still be awakened by the application of sensors or other stimulants. ${ }^{4}$

Culture and religion could shape how people sleep, with whom, where and when, as well as how people interpret quality sleep. People are considered to have quality sleep when they showed positive outcomes such as better health, less daytime sleepiness, improve the quality of life or well-being, and also better psychological function.$^{5}$ In the Western world, "a good night's sleep" is believed to be associated with good sleep hygiene, like being able to maintain body's natural rhythms, controlling exposure to light, getting regular exercise and controlling types of food and drink . ${ }^{6}$

From Islamic perspectives, sleep medicine is also considered an important issue, which, the Quran and Hadith discuss types of sleep, the importance of sleep and good sleep practices. Sleep is indeed the best form of rest for the human body after being tired from daily activities. A biological process that maintains the normal body clock, also known as 
"circadian rhythm", is moving actively in the brain and giving impacts on the human body .7 . In fact, sleep is a state where Allah Almighty holds a person's soul without giving him death, as stated in the Qur'an:

"God takes the souls (al-anfus) at the time of their death, and those that die not during their sleep; then He withholds those on whom He has passed the decree of death and sends the others back till an appointed term; most surely there are signs in this for a people who reflect." (39:42)

In other words, sleep phenomenon is associated with the metaphysical condition, of which, relates to the condition of the human body when the spirit leaves the body. While sleeping, the body and soul remain present while the spirit is lifted temporarily to the metaphysical world. When the spirit is reunited with the body, the body will awaken, as well as its' awareness and consciousness. ${ }^{8}$ Therefore, sleep can be considered as a gift from Allah Almighty to the mankind. As in the Qur'an, Allah says which means:

"It is out of His Mercy that He has put for you, night and day, that you may rest therein (i.e. during the night) and that you may seek of His Bounty (i.e. during the day), and in order that you may be grateful." (28:73)

Apart from food and drinks, sleep is also considered as a way to gain freshness and rejuvenate energy. Considering the importance of sleep in mankind as the best form of rest, the Prophet Muhammad (PBUH) taught us the appropriate etiquettes in getting quality sleep in accordance with the Islam demands. ${ }^{9}$ From Islamic perspectives, getting long sleep hours would not solely determine the efficiency and quality of sleep, however, it also depends on various other factors including following the modern sleep hygiene and the sleep etiquettes of Prophet Muhammad (PBUH). Therefore, this brief review was designed to provide an overview of quality sleep according to Islamic perspectives in relation to sleep hygiene as proposed by modern sciences.

\section{MATERIALS AND METHODS}

Peer-reviewed articles published over the last 15 years were conveniently retrieved from searches of computerized databases and search engines, such as Academic Search Complete, Google Scholar, PUBMED and Web of Science, in order to get a better understanding of the topic. It was believed that examining this issue and its related research simultaneously could reveal how sleep is important in both modern sciences and Islamic perspectives. Keywords included, "Sleep from Islamic perspective", "Sleep in modern science", "Sleep hygiene", "Western world and sleep", "Sleep deprivation" and "Quality sleep", for this search. Articles relevant to the topic were selected and were carefully read prior to ascertain their possible values. Articles which did not relate to the topic specifically, non-English manuscripts without an English abstract, or were not readily obtainable, were excluded. Selected articles were those deemed to support the relevance of conducting future analyses of this issue.

\section{RESULTS AND DISCUSSIONS}

A number of six $(n=6)$ articles were selected for this review (Table I).

Table I. Selected studies which were deemed to support the topic

\begin{tabular}{|c|c|c|c|}
\hline Author & Year & Country & Discussion/Content \\
\hline Tumiran et al. ${ }^{10}$ & 2015 & Malaysia & The concept of Qailullah (midday napping) in Islam. \\
\hline Mohd Yusof et al. ${ }^{9}$ & 2014 & Malaysia & $\begin{array}{l}\text { The phenomenon of sleep, including the importance, } \\
\text { sleeping times, sleeping positions and the etiquettes of } \\
\text { sleep from the view of Islam and Science. }\end{array}$ \\
\hline Rajab Nejad et al. ${ }^{11}$ & 2011 & Iran & $\begin{array}{l}\text { The role of sleep functions in human from the } \\
\text { perspective of Holy Quran. } \\
\text { Sleep therapy in Islam. }\end{array}$ \\
\hline BaHamman $^{12}$ & 2011 & Saudi Arabia & $\begin{array}{l}\text { Types and the importance of sleep from an Islamic } \\
\text { perspective. }\end{array}$ \\
\hline Tumiran et al. ${ }^{13}$ & 2010 & Malaysia & $\begin{array}{l}\text { Sleep from neuroscience and Islamic perspectives, } \\
\text { including the level of comprehension of sleep-related } \\
\text { concept by Muslims with the science background in } \\
\text { Malaysian education system. }\end{array}$ \\
\hline Stepanski \& Wyatt ${ }^{14}$ & 2003 & United States & Review on the use of sleep hygiene to treat insomnia. \\
\hline
\end{tabular}


Overview of sleep and quality sleep

Ideal sleep is defined as the optimal amount of sleep required for an individual to fully awake and remains alert, in order to function adequately throughout the day. ${ }^{15}$ Normally, the human circadian rhythm, that is, the biological clock in the body, is functioning to allow the body to feel tired and drowsy at night, and alertness during the daytime. The body clock is essentially controlled by "melatonin", a hormone produced by the pineal gland at night time. Melatonin causes sleepiness when it stimulated the hypothalamus in the brain. ${ }^{16}$ Naturally, darkness causes the body to generate more melatonin, thus hints the body to prepare for sleep. However, light could decrease melatonin production, and therefore, could also cause disruption to the circadian rhythm. These all, hence, could lead to sleep disturbances, increased food intake due to appetite-regulating hormonal changes and, decreased energy expenditure. ${ }^{15,16}$

In principle, people usually sleep at night, but it is possible to sleep during the day, depending on the condition. For example, in those who work on nightshift, they usually sleep during daytime. In modern sciences, average sleep requirements for an adult are approximately eight hours regardless of environmental or cultural differences. ${ }^{17}$ However, according to Islamic culture, nothing suggested that Muslims should go to bed and wake up at a certain time. Muslims were not forced to sleep a certain number of hours as well, although the natural average length is between $5-8$ hours for a 24 -hour period. ${ }^{18}$

But it is essential for Muslims to observe the five obligatory prayers per day. Therefore, sleeping time should be managed according to the prayers as well. The first prayer (Subh) is at dawn (about one hour before sunrise), hence Muslims have the responsibility to wake up early every day; weekdays and weekends. The last prayer (Isha) is in the evening, about 1.5-2 hours after sunset. ${ }^{12}$ In Islam, there are two periods when sleep is discouraged by the Prophet Muhammad (PBUH), that is, after Subh, and after Asr prayers. The Prophet (PBUH) did not sleep after Subh prayers as Allah Almighty give His blessing to those who work in the mornings. ${ }^{9}$ The Prophet (PBUH) asserted, as reported by alTabarani:

\section{"Work in the morning (Subh) in finding your fortune, as working in the morning brings blessings and success." 19}

According to Islam, productive Muslim sleep routine should follow three parts: one-third for Allah, onethird for ourselves and, one-third for our sleep. ${ }^{11,20}$ Activities like taking wudhu, brushing the teeth, putting on appropriate clothes and perfume, follow by praying Tahajjud and Witr, are meant for Allah Almighty. Other activities prior to going to sleep, such as putting on pyjamas (or wearing appropriate clothes for sleep), getting into bed and, reading a good book for at least 30 minutes, are often meant for ourselves, while reciting du'as and verses from the Quran, like Surah Al-Mulk, are supplications recommended for our sleep. ${ }^{11,20}$ These activities, as per Sunnah of Prophet Muhammad (PBUH), are recommended to ensure peaceful sleep hence lead to quality sleep, even though the activities are quite lengthy, which is about 90 minutes to be completed (30 minutes for each part).

\section{Qailullah}

According to Islamic perspectives, Qailullah, a short sleep activity occurring about an hour before Zuhr (the afternoon prayer) period or within the duration of Zuhr period (before Asr), is a deeply embedded practice, and recommended as one important daily activity in the Islamic culture .9,10,12,13 The Prophet Muhammad (PBUH) said, "Take a short nap, for devils do not take naps" [Sahih Aljamie. Alalbani 1647]. Another Hadith reported in Sahih Al-Bukhari (SB) asserted, "We used to offer the Jumua (Friday) prayer with the Prophet and then take the afternoon nap" [SB 5923]. Whereas in modern science, Qailullah, known as midday napping, is recommended particularly in conditions such as responses to sleep loss and, simply for relaxation after working in the morning.

Modern scientists reported that midday napping should occur between 2 p.m. and 4 p.m., and not after 4 p.m., or it will affect the ability of an individual to sleep at night. ${ }^{10,21}$ This is in accordance with Islamic recommendation and culture as well. It is also believed that midday napping could lead to considerable advantages in terms of mood, alertness and enhances memory tasks performance. $9,10,12,13$ However, midday napping should not be regarded as a long-term solution to maintain alertness and observance performance due to night sleep loss.

In general, Qailullah is being practiced by nonMuslims countries such as the United States of America (USA), Canada and even Japan, which is known as "power nap", or the power of a short sleep, in order to improve the productivity. ${ }^{22}$ After many years of research, the importance of Qailullah has been acknowledged by many, including nonMuslim countries. In the USA, the National Sleep Foundation (NSF) was established to increase awareness about the positive effects of daytime naps among the public.

\section{Sleep etiquettes and sleep hygiene}

In modern sciences, sleep deprivation is believed to contribute to deleterious effects on mental concentration, mood, memory, as well as the quality of life. This also has been emphasized in Islam, as asserted in one Hadith by the Prophet Muhammad (PBUH) in Sahih Al-Bukhari (SB):

\footnotetext{
"If anyone of you feels drowsy
} 


while praying he should go to bed
(sleep) till his slumber is
over" [SB 210].

Therefore, it is essential to have sufficient sleep. Various sleep hygiene has been recommended by modern sleep scientists as guidelines to ensure efficient and quality sleep, hence prevents the deleterious effects of sleep deprivation. For similar reasons, in Islamic culture, there are sleep etiquettes that Muslims could follow in order to be in accordance with the practice of the Prophet Muhammad (PBUH), as in Table II.

Table II. Examples of sleep etiquette as practiced by the Prophet Muhammad (PBUH) in accordance to sleep hygiene as recommended by modern sleep scientists

\begin{tabular}{ll}
$\begin{array}{l}\text { Sleep etiquettes / Sleep } \\
\text { hygiene }\end{array}$ & Islamic explanation \\
\hline
\end{tabular}

Early bedtime and early wake-up time

Performing ablution (Wudhu) and supplicating before going to sleep Dusting and cleaning the bed before sleeping

Sleeping position

Turning off light before sleep

Washing hands after waking up from sleep
"One should not sleep before the night prayer, nor have discussions after it" [SB 574].

"Whenever you go to bed, perform ablution like that for the prayer, and lie on your right side" [SM 2710].

"When anyone of you goes to bed, he should take hold of the hem of his lower garment and then should clean (his bed) with the help of that and then should recite the name of Allah" [SM 271].

"Whenever you go to bed, perform ablution like that for the prayer, and lie on your right side" [SM 2710) "When the Prophet (PBUH) wants to go to sleep, he puts his right hand under his cheek" [SM 2713].

\begin{abstract}
"Put out lamps when you go to bed, shut the doors, and cover water and food containers" [SB 5301]
\end{abstract}

"When you wake up from sleep to pray, wash your hands before you put them in the wudhu water, for you do not know where your hands have spent the night." [Narrated by Abu Hurairah]
To get sufficient sleep, hence reduce the risks of getting chronic diseases.

To relax the body thus prepares it for a deep sleep.

To get rid of bed bugs or insects that could lead to skin problem, such as scabies.

It is recommended to lie down on the right side. This is because the human left lung is smaller than the right lung, hence by lying on the right side, it can reduce the pressure to the heart while sleeping. In addition, lying down on the abdomen can cause shortness of breath, while lying down on the back can cause the respiration to be through the mouth and increase the snoring rate.

To maintain a dark environment during sleep, in order not to disrupt the circadian rhythm.

During sleep, germs may accumulate on the hands, therefore washing hands is essential.

\section{CONCLUSION}

Sleep is a natural biological phenomenon that is important in our lives. People may be able to refrain from food or drinks for a few days, but not from sleeping. From Islamic perspectives, sleep, whether on the importance, the time and duration, the sleeping position, the sleep etiquette, or other sleep-related aspects, can be proven through modern sciences. The Quran and science are both required and inseparable, and their connection should be well-balanced. Islam emphasizes that sleep is one of the gifts given by Allah Almighty to human beings, in order to take care of one's health for the survival and maintain the quality of life. Therefore, sleep deprivation and not getting quality sleep could lead to many consequences such as insomnia and sleep apnea, as well as other chronic diseases.

\section{REFERENCES}

1. Ar-Raghib al-Isfahani Al-Mufradat fi Garib alQuran Jilid 2660 Makkah al-Mukarramah: Maktabah Nizar Mustafa al-Bazz 1997.

2. Al-Kindi, Abu Yusuf Ya 'qub ibn Ishaq al-Sabah.Fi Mahiyah an-Naum wa al-Ra'yu. In Rasa'il alKindi al-Falsafiyah 294-308.

3. Roger B, Sejnowski T, Siegel J, et al Waking up to sleep In: The Science Network [online]. Available at: http://thesciencenetwork.org/ programs/waking-up-to-sleep. Accessed 25 September, 2016.

4. Dinges, DF, Broughton, RJ Sleep and Alertness: Chronobiological, Behavioral and Medical Aspects of Napping. New York: Raven Press 1989.

5. Hyyppa MT, Kronholm E Quality of sleep and chronic illnesses. J Clin Epidemiol 1989; 42:633- 
8.

6. Thomas Y Get a good night's sleep: 7 Practical Steps. [online]. Available at: http:// www.sleepcouncil.org.uk/wp-content/ uploads/2013/01/Get-a-Good-Nights-Sleep.pdf. Accessed 25 September, 2016.

7. Wirz-Justice A. How to measure circadian rhythm in humans. Medicographia 2007; 29 (1): 84-90

8. Ahmad Syauqi Ibrahim Al-Syifa'un Nafsi wa Asrarun Naum. 79. Cairo: Dar al-Fikr al- 'Arabi. 2002.

9. Mohd Yusof F, Muhamad SN, Rosman AS, et al. 2014. Sleep Phenomena from the Perspectives of Islam and Science. Jurnal Teknologi (Sciences \& Engineering) 2014; 67(1): 105-10

10. Tumiran MA, Abdul Rahman NN, Mohd Saat R, et al. The concept of Qailulah (midday napping) from Neuroscientific and Islamic perspective. J Religion Health 2015. DOI 10.1007/s10943-0150093-7

11. Rajab Nejad M, Rajab Nejad S, Rastegar F The role of sleep functions in human health from the perspective of the Holy Quran. Quran Med 2011; 1(2):30-5. DOI:10.5812/quranmed.4980

12. BaHammam AS Sleep from an Islamic Perspective. Ann Thorac Med 2011; 6(4): 187-92

13. Tumiran MA, Mohd Saat R, Abdul Rahman NN, Hasan Adli DS. Sleep from neuroscience and Islamic perspectives: comprehension and practices of Muslims with science background in Malaysian education system. Procedia Social and Behavioral Sciences 2010; 9: 560-4

14. Stepanski EJ, Wyatt JK Use of sleep hygiene in the treatment of insomnia. Sleep Med Rev 2003; 7 (3): 215-25

15. Marks R, Landaira M Sleep, disturbances of sleep, stress and obesity: a narrative review. 2015. J Obesity Eating Disorders 1(2:2): 1-6

16. Iglowstein, I, Oskar G, Jennie MD, et al. Sleep Duration from Infancy to Adolescence: Reference Values and Generational Trends. Pediatrics 2003; 111(2): 302-7. DOI: 10.1542/ peds.111.2.302. PMID 12563055.

17. De Benedictis T, Larson H, Kemp G, Barston S, Segal R. Understanding Sleep: Sleep Needs, Cycles, and Stages. Available at: http: / / www.helpguide.org/life/sleeping.htm. Accessed 25 February 2017.

18. Islam Question and Answer. Available at: https://islamqa.info/en/96589. Accessed 14 January 2017.

19. Al-Tabrani, Abi Qasim Sulaiman bin Ahmad. Mu'jam al-Awsat. 279. Jilid 8. Kaherah: Dar alHaramain. 1995.

20. Productive Muslim Sleep Routine. Available at: http://productivemuslim.com/ productivemuslim-sleep-routine/. Accessed 15 January 2017.

21. Samuels $\mathrm{CH}$, Alexander BN Sleep, recovery and human performance. Available at: http:// www.canadiansportforlife.ca/. Accessed 30 February 2017.

22. Berita Harian, 1 Mei 2012, h.15. 
